\title{
Novel Membrane Reactor with Filamentous Catalytic Bed for Propane Dehydrogenation
}

\author{
O. Wolfrath, ${ }^{\dagger}$ L. Kiwi-Minsker, ${ }^{\ddagger}$ and A. Renken* \\ Laboratory of Chemical Reaction Engineering, Swiss Federal Institute of Technol ogy, \\ $\mathrm{CH}-1015$ Lausanne, Switzerland
}

\begin{abstract}
A novel membrane reactor with two zones containing structured filamentous catalytic beds was proposed for propane nonoxidative dehydrogenation. Catalytic filaments with a $\sim 7-\mu$ m diameter consist of silica covered by porous alumina with $0.5 \% \mathrm{Pt} / 1 \% \mathrm{Sn}$. These filaments were placed in parallel in a tubular membrane reactor. The hydrodynamic characteristics of the reactor correspond to the properties of a multichannelled microreactor with laminar flow, a low pressure drop, and a narrow residence time distribution. A propane conversion of 0.34 at $823 \mathrm{~K}$ was reached, instead of the 0.24 equilibrium value. The catalyst demonstrated a suitable stability under periodic regeneration in oxidative atmosphere.
\end{abstract}

\section{Introduction}

The increasing demand for propene and propene derivatives requires further development of available technologies taking into account the process efficiency, environmental impact, and operating simplicity. Production of propene via nonoxidative catalytic dehydrogenation of propane has technological constraints because (1) the reaction is highly endothermic; (2) the thermodynamic equilibrium limits the conversion; and (3) at the temperatures required by the reaction thermodynamics, thermal cracking occurs, thus lowering the catalyst activity by coke deposition on the catalyst surface, which necessitates periodic regeneration.

Any development of catalytic propane dehydrogenation technology has to consider (1) the supply of sufficient heat, (2) the avoidance of decomposition of the feed and effluents, (3) the minimization of the pressure drop in the catalytic bed, (4) the optimization of the catalyst formulation working at the desired temperature and with reasonable operational lifetimes, and (5) the burning off of coke from the catalyst surface without al tering its activity/sel ectivity.

Therefore, reactor engineering has to be integrated with the catalyst design. Herein, we report a novel reactor design for the nonoxidative dehydrogenation of hydrocarbons. The reactor concept combines the advantages of membrane reactors (shifting the equilibrium and/or lowering the working temperature) with optimal fluid dynamics ensuring laminar flow and a narrow residence time distribution during periodic reactor operation. This specific reactor design calls for a specific catalyst structure in the form of long-length filamentous threads.

The aim of this work is a twofold: (i) first, to develop catalysts in the filamentous form that are active/ selective in propane nonoxidative dehydrogenation, and (ii) second, to design a periodically operated membrane

* Corresponding author: Albert Renken, IGC-DC-EPFL, CH-1015 Lausanne, Switzerland. E-mail: Albert.Renken@ epfl.ch. Phone: +41 21693 3181. Fax +41 216933190.

†E-mail: Olivier.Wolfrath@epfl.ch. Phone: +41 21693 3694. Fax: +41216933190.

‡E-mail: Lioubov.Kiwi-Minsker@epfl.ch. Phone: +41 21 693 3182. Fax: +41216933190.

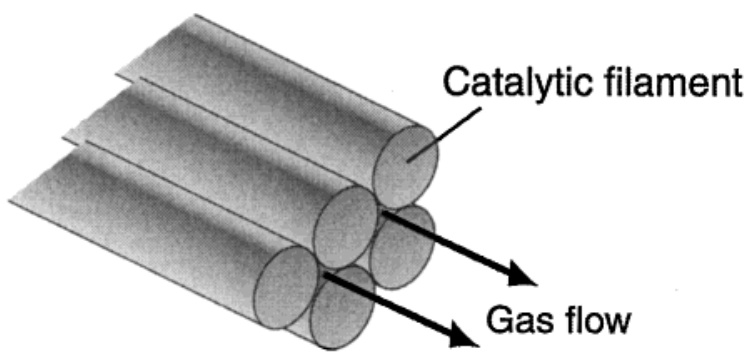

Figure 1. Axial flow of gases between catalytic filaments.

reactor with a filamentous catalytic bed. The main hydrodynamic parameters of the reactor (pressure drop and residence time distribution) have al so been studied.

\section{Reactor Concept}

The reactor proposed in this study has the following main features: (1) Two zones are separated by a membrane permeable to hydrogen. (2) Both zones are filled with the same filamentous catalyst oriented parallel to the reactor walls. (3) Gas passes along the filaments, ensuring the axial laminar flow shown in Figure 1. (4) Reaction and regeneration are carried out in a cyclic mode by switching the reaction mixture from one zone to another.

The structured catalytic bed arranged with parallel filaments of few micrometers in diameter $(7 \mu \mathrm{m})$ should present flow hydrodynamics similar to that of a multichannel microreactor. These reactors are known to have a laminar flow and a short radial diffusion time, resulting in a narrow residence time distribution (RTD) ${ }^{1,2}$ In fact, the channels for gas flow between the filaments (see Figure 1) have an equival ent hydraulic diameter in the range of a few micrometers, thus ensuring laminar flow. As a consequence, the radial diffusion time from the gas phase to the surface of the nearest filaments is also short because of the diffusion distance of some micrometers.

The reactor design is schematically presented in Figure 2. The two zones of the tubular reactor are separated by a Pd/Ag membrane permeable to hydrogen. On one side of the membrane (zone I), the dehydroge nation takes place, with simultaneous coke formation 


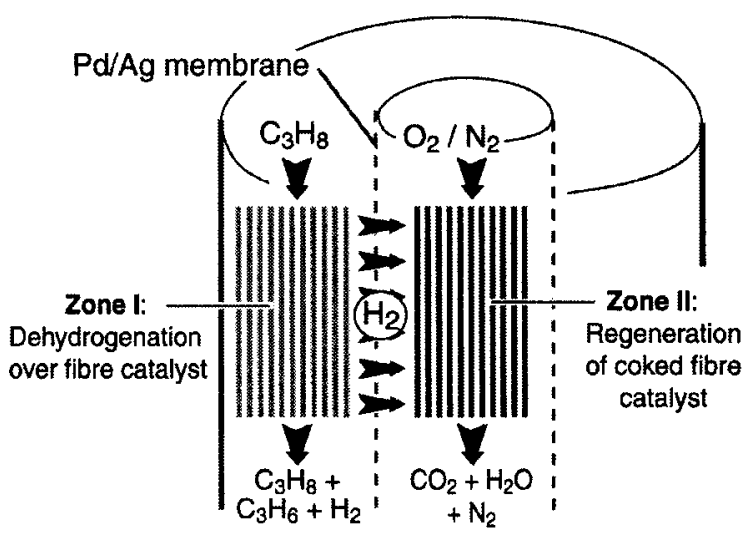

Figure 2. Scheme of the membrane reactor with a two-zone filamentous catalytic bed.

on the catalyst surface and diffusion of hydrogen to zone II. On the other side of the membrane (zone II), hydrogen is oxidized in an oxygen/nitrogen gas mixture, thus generating heat for the endothermic dehydrogenation in zone I. Moreover, because of the permanent oxidation of hydrogen, a high radial gradient in the hydrogen concentration is obtained. This gradient allows for the efficient removal of hydrogen from the reaction zone and a consequent shift of the reaction equilibrium. Simultaneously with the hydrogen oxidation, the deactivated catalyst is regenerated by the burning off of coke from the catalyst surface. The feeds of oxygen and propane are switched periodically between the two zones.

The catalytic filaments with a diameter of $\sim 7 \mu \mathrm{m}$ consist of a silica core covered by a $\gamma$-alumina porous layer on which an active phase (Pt/Sn) is located. ${ }^{3}$

\section{Experimental Section}

3.1. Catalyst Preparation and Characterization. Aluminoborosilicate glass fibers in woven form (Vetrotex France SA) with a specific surface area (SSA) of $\sim 2 \mathrm{~m}^{2}$ $\mathrm{g}^{-1}$ were used as the starting material for the preparation of the catalytic support. First, the fabrics were treated at $90{ }^{\circ} \mathrm{C}$ in $1.0 \mathrm{~N}$ aqueous solutions of $\mathrm{HCl}$ to leach out the non-silica components of the glass; then, the material was rinsed in distilled water and dried in air at $50{ }^{\circ} \mathrm{C}$ overnight. ${ }^{4}$ The specific surface area was increased by this procedure up to $290 \mathrm{~m}^{2} \mathrm{~g}^{-1}$, indicating that porous filaments were obtained. The filaments' surfaces were then covered by $\gamma$-alumina via deposition/ precipitation of aluminum hydroxide from an aqueous solution of a suitable salt, followed by drying and calcination in air at $650^{\circ} \mathrm{C}$ for $3 \mathrm{~h}$. The resulting support material, alumina/silica filaments (ASFs), is mechanically stable up to $800^{\circ} \mathrm{C}$, compared to the starting glass fiber, which becomes soften at temperatures of ca. 400 ${ }^{\circ} \mathrm{C}$. The SSA of the final material is in the range of $100-$ $230 \mathrm{~m}^{2} \mathrm{~g}^{-1}$.

The active metals (Pt and Sn) were deposited via a two-step impregnation from aqueous ammonia solutions $(\mathrm{pH}=10) . \mathrm{SnCl}_{2}$ and hexachloroplatinic acid $\left(\mathrm{H}_{2} \mathrm{PtCl}_{6}\right)$ (purum, Fluka Chemie AG, Buchs, Switzerland) were used as precursors. Impregnation was followed by drying at $50{ }^{\circ} \mathrm{C}$ overnight and calcination at $450{ }^{\circ} \mathrm{C}$ in air for $1 \mathrm{~h}$. The concentrations of the solutions were adjusted to attain a catalyst formulation of $0.5 \% \mathrm{Pt} / 1 \%$ $\mathrm{Sn}$ on ASF. This composition was reported to be selective toward propene and to have acceptable stability with time-on-stream. ${ }^{3}$

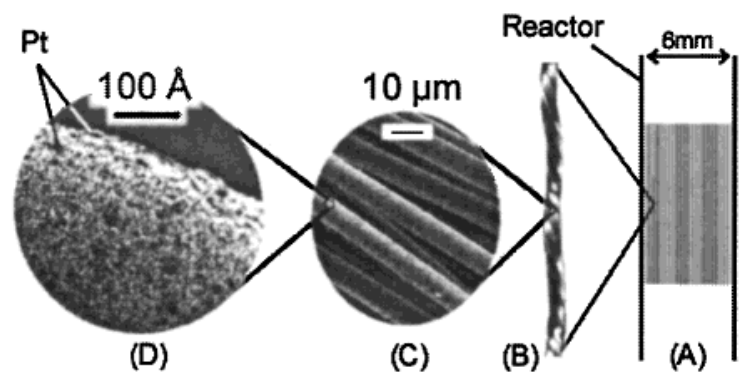

Figure 3. $\mathrm{Pt} / \mathrm{Sn}$ deposited on alumina-silica filamentous (ASF) support in the form of bundled threads placed inside the cylindrical tube reactor.

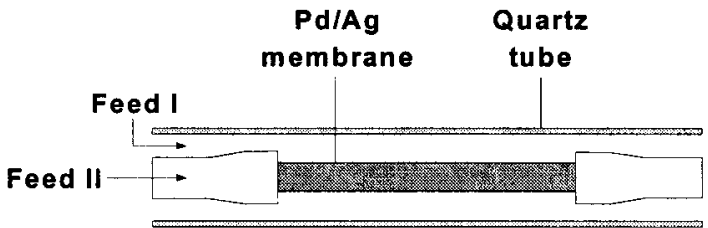

Figure 4. Scheme of the membrane reactors.

3.2. Structured Catalytic Bed. The catalytic filaments were introduced into the tubular reactor in the form of threads (see Figure 3B). Each thread with a diameter of about $0.5 \mathrm{~mm}$ consists of a bundle of $\sim 100$ filaments (Figure $3 \mathrm{C}$ ), each with a diameter of $\sim 7 \mu \mathrm{m}$. The surfaces of the filaments are covered by $\gamma$-alumina with the active metals $\mathrm{Pt} / \mathrm{Sn}$ (Figure 3D). The catalytic threads were placed in parallel into the cylindrical tubular reactor (Figure $3 \mathrm{~A}$ ). The catalytic bed arranged in this manner had about 300 threads per $\mathrm{cm}^{2}$ within the tube cross section. The porosity of the filamentous packed bed is $\epsilon \approx 0.8$. The catalyst surface area per unit volume was measured by BET experiments and is on the order of $10^{8} \mathrm{~m}^{2} / \mathrm{m}^{3}$ and about 1.5 orders of magnitude higher than that of washcoated tubes of the same diameter. ${ }^{5}$

3.3. Membrane Reactor. The membrane used in this study consists of a $\mathrm{Pd} / 23 \% \mathrm{Ag}$ all oy in the form of a tube with a wall thickness of $70 \mu \mathrm{m}(\mathrm{J}$ ohnson Matthey and Brandenberger SA, Zürich, Switzerland). The hydrogen flow through such a membrane was found to be proportional to the difference of the square roots of the hydrogen partial pressures on the two sides of the membrane. The following equation ${ }^{6}$ is suggested for estimation of the hydrogen flux

$$
\mathrm{F}=4.08 \times 10^{-8} \mathrm{e}^{-327 \pi} \frac{\sqrt{\mathrm{p}_{\mathrm{l}}}-\sqrt{\mathrm{p}_{\mathrm{II}}}}{\mathrm{t}_{\mathrm{memb}}}\left(\mathrm{mol} \mathrm{m}^{-2} \mathrm{~s}^{-1}\right)
$$

where $T$ is the temperature $(K)$; $t_{\text {memb }}$ is the membrane thickness $(m)$; and $p_{\mathrm{I}}$ and $p_{\mathrm{II}}$ are the hydrogen partial pressure in zones I and II (Pa), respectively (cf. Figure 2). The reactor is schematically presented in Figure 4. It has a length ( $L$ ) of $140 \mathrm{~mm}$ and an internal diameter (ID) of $6 \mathrm{~mm}$. It is inserted in a quartz tube with an internal diameter of $8.6 \mathrm{~mm}$. The interstitial volume (a shell) represents zonel (Figure 2). The tube and shell volumes are equal to $4.0 \mathrm{~mL}$, and both could be filled by catalytic filaments.

3.4. Experimental Setup and Procedure. The experimental setup is schematically presented in Figure 5. It consists of four main parts: (1) the supply of gases (propane, oxygen, and nitrogen) via mass flow controllers, (2) the reactor, (3) the analytical part equipped with a GC (H P6890 Series, Supel co Carboxen 1010 col umn), 


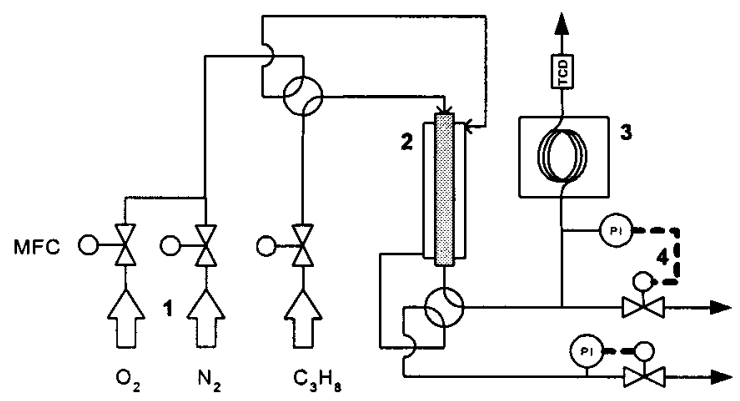

Figure 5. Experimental setup for propane dehydrogenation.

and (4) pressure regulators. A four-way valve is used to switch the two feeds (propane and oxygen/nitrogen).

For catalyst screening, a quartz tube $(6 \mathrm{~mm} I D, 450$ $\mathrm{mm}$ length) was used as a plug-flow reactor. The reaction was carried out at temperature of $823 \mathrm{~K}$ and an absolute pressure of $0.14 \mathrm{MPa}$. The catalyst (375$630 \mathrm{mg}$ ) was introduced into the middle part of the reactor in the form of fibers or powder. Before the reaction, the catalyst was heated under a nitrogen flow at $10 \mathrm{~K} / \mathrm{min}$ to the reaction temperature. After $15 \mathrm{~min}$ of temperature stabilization, the flow of nitrogen was replaced by a flow of pure propane, and the reaction products were monitored.

After about $4 \mathrm{~h}$ on-stream, the catalyst was regenerated by passing a mixture of $5 \% \mathrm{O}_{2}$ in $\mathrm{N}_{2}$ at the reaction temperature through the reactor. The only product observed in the outlet of the reactor during regeneration was $\mathrm{CO}_{2}$. The regeneration time depends on the catalyst used and the degree of deactivation observed. In most cases, a 4-h regeneration was sufficient to completely burn off the deposited coke. The conversion of propane was calculated according to eq 2 . The calculation does not consider the conversion of propane to coke, as its instantaneous formation is time-dependent and difficult to estimate. Therefore, the calculation is based on the propane conversion to propene, ethane, ethene, and methane. The relative error is estimated to be on the order of $2-4 \%$.

$$
\begin{aligned}
& \mathrm{X}_{\mathrm{C}_{3} \mathrm{H}_{8}}=\frac{\mathrm{n}_{\mathrm{C}_{3} \mathrm{H}_{8}}^{\text {in }}-\mathrm{n}_{\mathrm{C}_{3} \mathrm{H}_{8}}^{\text {out }}}{\mathrm{n}_{\mathrm{C}_{3} \mathrm{H}_{8}}^{\text {in }}} \approx \\
& \frac{\mathrm{y}_{\mathrm{C}_{3} \mathrm{H}_{6}}+{ }^{2} / 3 \mathrm{y}_{\mathrm{C}_{2} \mathrm{H}_{6}}+{ }^{2} /{ }_{3} \mathrm{y}_{\mathrm{C}_{2} \mathrm{H}_{4}}+{ }^{1} /{ }_{3} \mathrm{y}_{\mathrm{CH}_{4}}}{\mathrm{y}_{\mathrm{C}_{3} \mathrm{H}_{8}}+\mathrm{y}_{\mathrm{C}_{3} \mathrm{H}_{6}}+{ }^{2} /{ }_{3} \mathrm{y}_{\mathrm{C}_{2} \mathrm{H}_{6}}+{ }^{2} /{ }_{3} \mathrm{y}_{\mathrm{C}_{2} \mathrm{H}_{4}}+{ }^{1} / \mathrm{y}_{\mathrm{CH}_{4}}} \\
& \mathrm{~S}_{\mathrm{i}}=\frac{\mathrm{n}_{\mathrm{i}}^{\text {out }}}{\mathrm{n}_{\mathrm{C}_{3} \mathrm{H}_{8}}^{\text {in }}-\mathrm{n}_{\mathrm{C}_{3} \mathrm{H}_{8}}^{\text {out }}} \frac{\mathrm{c}_{\mathrm{i}}}{3} \approx \\
& \frac{\frac{\mathrm{c}_{i}}{3} \mathrm{y}_{\mathrm{i}}}{\mathrm{y}_{\mathrm{C}_{3} \mathrm{H}_{6}}+{ }^{2} / \mathrm{y}_{\mathrm{C}_{2} \mathrm{H}_{6}}+{ }^{2} / \mathrm{y}_{\mathrm{C}_{2} \mathrm{H}_{4}}+{ }^{1} / 3 \mathrm{y}_{\mathrm{CH}_{4}}}
\end{aligned}
$$

The selectivities toward the formation of different products were calculated according to eq 3 , where $c_{i}$ is the number of carbon atoms in compound i. Here, too, the coke formation is neglected.

Residence time distribution experiments were performed by measuring the response to a step function $\left(10 \% \mathrm{Ar}\right.$ in $\mathrm{N}_{2}$ ) with a quadrupole mass spectrometer (TSU 260D, Balzers, Balzers, Liechtenstein).

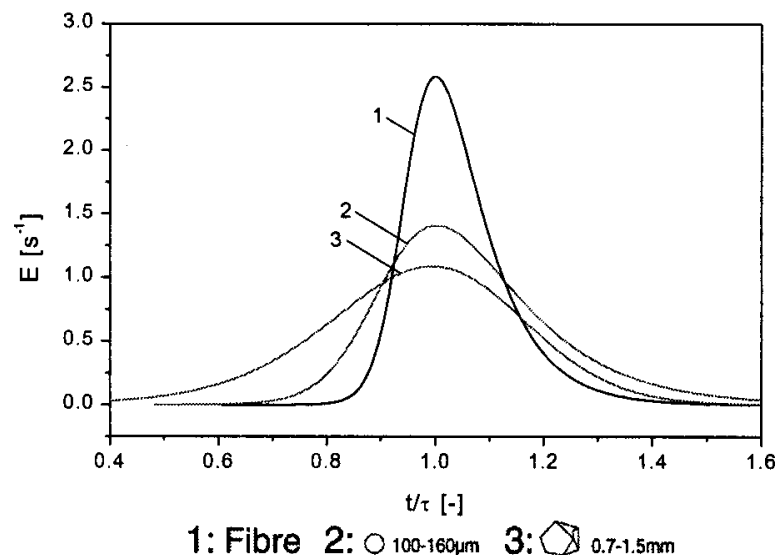

Figure 6. RTD for the randomly packed beds in comparison with that for the structured filamentous bed: response of the switch at $30 \mathrm{~mL} / \mathrm{min}$ (STP) from $10 \% \mathrm{Ar} / \mathrm{N}_{2}$ to $\mathrm{N}_{2} ; 298 \mathrm{~K}, 0.1 \mathrm{MPa}$, internal tube diameter $=15 \mathrm{~mm}$, length $=230 \mathrm{~mm}$.

\section{Results and Discussion}

4.1. Hydrodynamics and Residence Time Distribution. The main drawbacks of randomly packed beds are the high-pressure drop and various flow maldistributions, resulting in a broad residence time distribution (RTD). ${ }^{7}$ The longitudinal arrangement of filaments in the tube reactor gives a structure of parallel microchannels with a hydraulic diameter corresponding to the diameter of filaments. In the present study, the microchannels have a diameter in the range of a few micrometers, thus ensuring laminar gas flow. In such channels, the radial diffusion time is short (on the order of $10^{-1} \mathrm{~s}$ ). Therefore, a narrow residence time distribution can be expected.

The RTD was measured in a tube packed with fibrous catalysts and with granules of silica and $\gamma$-alumina of different shapes and sizes. Under identical experimental conditions, all randomly packed beds demonstrated a significantly broader RTD compared to that of the structured filamentous packing. As an example, in Figure 6, the experimentally obtained RTD for a filamentous catalytic bed (curve 1 ) is presented. The much narrower RTD over ASF is clearly seen in comparison with the RTDs for the randomly packed beds (curves 2 and 3).

The pressure drop during the passage of gas through the tube packed with spheres of 100-160- $\mu \mathrm{m}$ diameter was also measured and compared to the pressure drop through the structured filamentous packing. The hydraulic diameters of the two beds are on the same order of magnitude. For the same conditions as indicated in Figure 6 the pressure drops at $120 \mathrm{~mL} / \mathrm{min}$ (STP) were found to be

$$
\begin{array}{ll}
100-160-\mu \mathrm{m}-\text { sphere bed } & \Delta p=36 \times 10^{2} \mathrm{~Pa} \\
\text { filamentous bed } & \Delta p=7.0 \times 10^{2} \mathrm{~Pa}
\end{array}
$$

The pressure drop measured for the structured microchannel reactor can be used to estimate the equivalent diameter of the channels under laminar flow based on the well-known relationship of Hagen-Poisieulle

$$
\mathrm{d}_{\mathrm{eq}}=\sqrt[4]{\frac{128 \mathrm{Q} \mu \mathrm{L}}{\pi \Delta \mathrm{p}}}
$$


Table 1. Main Characteristics of Different Catalysts Tested in Propane Dehydrogenationa

\begin{tabular}{clcccrr}
\hline no. & \multicolumn{1}{c}{ sample } & porosity & $\begin{array}{c}\mathrm{SSA} \\
\left(\mathrm{m}^{2} \mathrm{~g}^{-1}\right)\end{array}$ & $\begin{array}{c}\text { initial } \\
\text { conversion }\end{array}$ & $\begin{array}{c}\text { conversion lost } \\
\text { after } 2 \mathrm{~h}(\%)\end{array}$ & $\begin{array}{c}\text { propene } \\
\text { selectivity }\end{array}$ \\
\hline 1 & $1.0{\mathrm{Pt} / \mathrm{Al}_{2} \mathrm{O}_{3} \text { powder }}$ & 0.77 & 167 & 0.24 (equil) & 67.6 & 0.68 \\
2 & $0.5 \mathrm{Pt} / 1.0 \mathrm{Sn} / \mathrm{Al}_{2} \mathrm{O}_{3}$ powder & 0.80 & 153 & 0.24 (equil) & 8.5 & 0.88 \\
3 & $0.5 \mathrm{Pt} / 1.0 \mathrm{Sn} / \mathrm{ASF}$ & 0.83 & 208 & 0.24 (equil) & 8.3 & 0.93
\end{tabular}

a $823 \mathrm{~K}, 0.14 \mathrm{MPa}, \mathrm{GHSV}=1170 \mathrm{~h}^{-1}$.

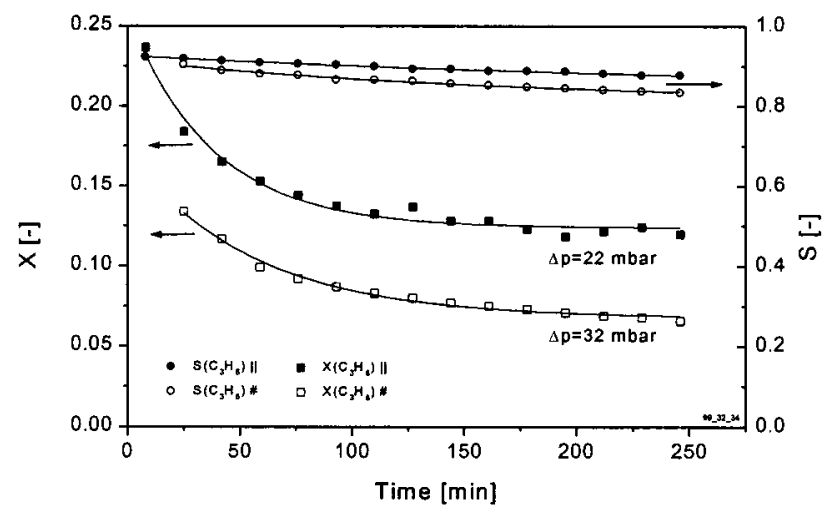

Figure 7. Influence of fiber orientation in the reactor on propane conversion for $0.5 \% \mathrm{Pt} / 1 \% \mathrm{Sn} / \mathrm{ASF}$ with time-on-stream; reactor inlet $=100 \%$ propane, GHSV $=679 \mathrm{~h}^{-1}(\tau=5.3 \mathrm{~s}), 823 \mathrm{~K}, 0.14$ $\mathrm{MPa}, \mathrm{I}_{\text {cat }}=57 \mathrm{~mm}$. \# corresponds to rolled tissue and $\|$ to the filaments oriented parallel.

The estimated equivalent diameter of the microchannels in the filamentous catalytic bed was found to be $\mathrm{d}_{\mathrm{eq}} \approx$ $70 \mu \mathrm{m}$.

4.2. Propane Dehydrogenation. 4.2.1. Catalyst Testing. The catalyst performances were tested in a quartz tubular reactor (ID $=6 \mathrm{~mm}$ ) at a temperature of $823 \mathrm{~K}$. The mass of catalyst and the space time were kept constant for all runs. With fresh catalyst, the equilibrium conversion was attained for all runs. As a result of coke formation, the activity decreased with time-on-stream, resulting in some loss of conversion (Table 1). Addition of Sn to Pt is seen to increase the selectivity toward propene, together with the catalyst stability. The filamentous catalyst Pt/Sn/ASF was found to have the same activity and stability as powdered $0.5 \%$ $\mathrm{Pt} / 1.0 \% \mathrm{Sn} / \mathrm{Al}_{2} \mathrm{O}_{3}$ catalyst, while the sel ectivity is even increased from 0.88 to 0.93 .

To compare the performance of the structured packing with that of a randomly packed filamentous catalyst, the catalyst was introduced into the reactor in the form of rolled tissue. The results obtained are summarized in Figure 7. Both experiments led to comparable selectivities toward propene, but in the randomly packed catalytic bed, the conversion of propane was about $50 \%$ lower. The differences can be partially explained by a more uniform RTD. Furthermore, the packing with rolled catalytic tissues was not homogeneous, leading to the maldistribution of catalyst and, eventually, poor contact between reactant and catalyst.

Figure 8 shows the dependence of propane conversion on time-on-stream during dehydrogenation over $0.5 \%$ $\mathrm{Pt} / 1 \% \mathrm{Sn} / \mathrm{ASF}$. The initial conversion corresponds to the equilibrium value $X_{\text {eq }}=0.24$ under the reaction conditions used. ${ }^{8}$ The conversion decreases to $X=0.14$ during the first 100 min on-stream and reaches $X=0.12$ after $250 \mathrm{~min}$. The propene selectivity decreases sl owly with time from 0.92 initially to 0.88 after $250 \mathrm{~min}$. The byproducts detected in the effluents were methane, ethane, and ethene.

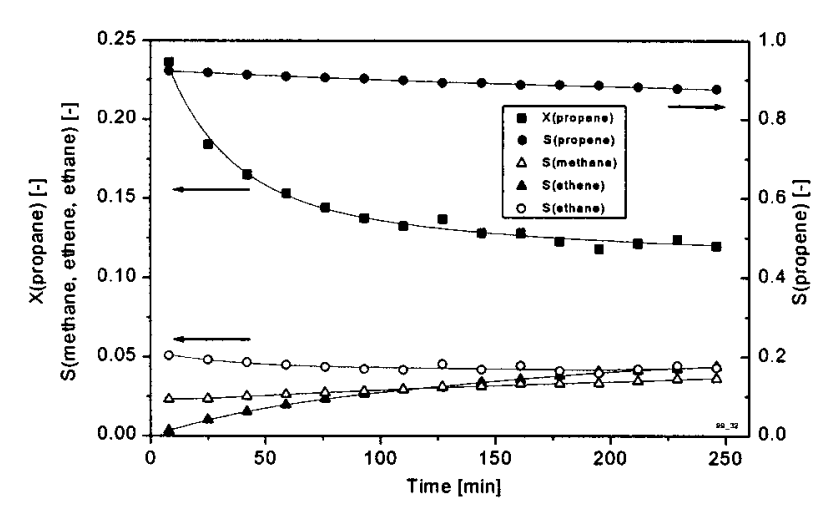

Figure 8. Propane conversion and product selectivities over $0.5 \%$ $\mathrm{Pt} / 1 \% \mathrm{Sn} / \mathrm{ASF}$ (filaments oriented parallel) with time-on-stream; reactor inlet $=100 \%$ propane at $6.3 \mathrm{~mL} / \mathrm{min}(\mathrm{STP}) ; \mathrm{GHSV}=735$ $\mathrm{h}^{-1}(\tau=4.9 \mathrm{~s}), 823 \mathrm{~K}, 0.14 \mathrm{MPa}, \mathrm{I}_{\text {cat }}=30 \mathrm{~mm}$.

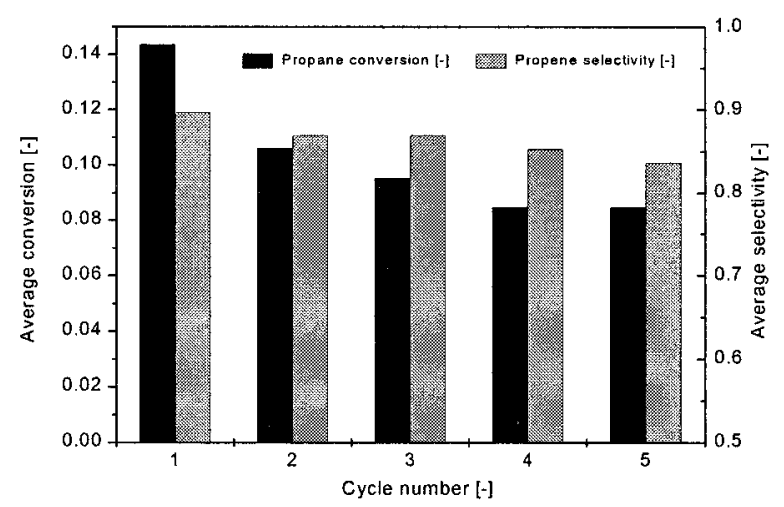

Figure 9. Cyclic dehydrogenation-regeneration with the same ASF catalyst; GHSV $=735 \mathrm{~h}^{-1}(\tau=4.9 \mathrm{~s}), 823 \mathrm{~K}, 0.14 \mathrm{MPa}$, inlet $=100 \%$ propane at $6.3 \mathrm{~mL} / \mathrm{min}$ (STP).

4.2.2. Catalyst Deactivation and Regeneration. The loss of activity is due to the deposition of coke on the catalyst surface, which can be removed by oxidation. The catalyst regeneration was performed by replacing the propane flow with a flow of $5 \% \mathrm{O}_{2}$ in $\mathrm{N}_{2}$ at $823 \mathrm{~K}$. It took about $4 \mathrm{~h}$ until the amount of $\mathrm{CO}_{2}$ at the outlet of the reactor dropped to a negl igible value, indicating that the coke was burned off completely. Thus, the switch between the two feeds (propane and oxygen) was performed every $4 \mathrm{~h}$, resulting in a cycle time of $8 \mathrm{~h}$.

Figure 9 presents five cycles of dehydrogenation/ regeneration. The residence time, referred to a packed tube with a porosity of $\epsilon=0.83$, was kept relatively short (4.9 s) to attain a low conversion of propane so that the catalyst activity after each regeneration could be compared. The highest activity was reached with fresh catalyst. After each regeneration during first three cycles, some loss of activity was observed, but the propane conversion remained stable afterward. The propene selectivity was essentially not altered by regeneration.

These results indicate that the catalyst formulation is a crucial point in the development of the process of nonoxidative dehydrogenation of hydrocarbons. 


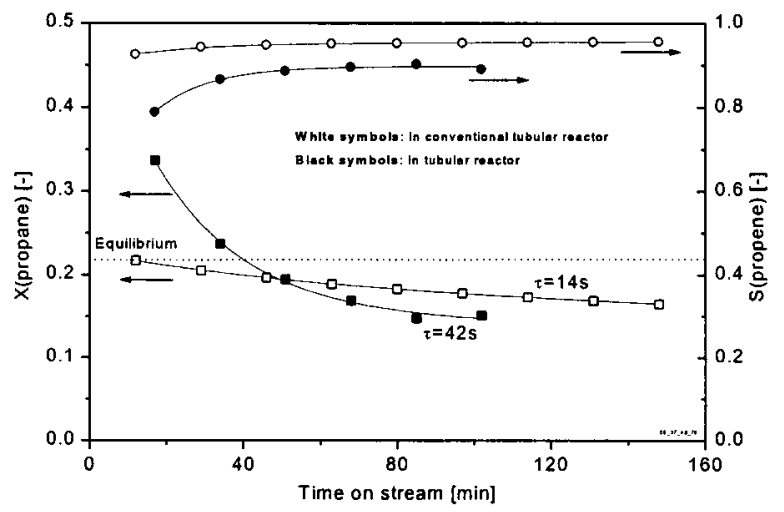

Figure 10. Enhancement of propane conversion with membrane reactor at $823 \mathrm{~K}$ and $0.14 \mathrm{MPa}$; feed II = propane at $5.6 \mathrm{~mL} / \mathrm{min}$ $(\mathrm{STP})(\tau \approx 14 \mathrm{~s})$ in the conventional reactor and $2.0 \mathrm{~mL} / \mathrm{min}$ (STP) $(\tau \approx 42 \mathrm{~s})$ in membrane reactor; feed $\mathrm{I}=\mathrm{O}_{2}$ at $4.0 \mathrm{~mL} / \mathrm{min}(\mathrm{STP})$ in the membrane reactor.

4.2.3. Propane Dehydrogenation over $\mathrm{Pt} / \mathrm{Sn} / \mathrm{ASF}$ in the Membrane Reactor. The membrane reactor described above (Figure 4) was tested for propane dehydrogenation. In a blank experiment in which the tubular reactor was filled with nonimpregnated filaments, the conversion did not exceed $0.6 \%$. This shows that the catalytic activity of the membrane itself can be neglected under the reaction conditions used.

In Figure 10, the results obtained in the membrane reactor are compared to those for a conventional reactor packed with the same fibrous catalyst. Using the membrane reactor and increasing the residence time from 14 to $42 \mathrm{~s}$ allowed the equilibrium conversion of $X_{\text {eq }}=0.24$ to be exceeded within the first $50 \mathrm{~min}$. The catalyst deactivation was observed to be faster in the membrane reactor. Within the first $50 \mathrm{~min}$, the propane conversion decreased from 0.34 initially to ca. 0.2 . This can be explained by a higher coke formation rate resulting from the lower concentration of hydrogen in the gas phase. ${ }^{9}$ The slightly lower propene selectivity can be explained by the high residence time, which favors the consecutive reaction of propene to lighter compounds.

Because diffusion of gas between the filaments in the radial direction is possible, a radial gradient of the hydrogen concentration from the middle of the catalytic bed to the membrane wall will develope. One might expect that this would lead to an enlargement of the RTD. However, because of the short diffusion time from the middle of the bed to the membrane $(<1 \mathrm{~s})$ and the high permeability of the membrane, the concentration gradient is very low (a mean concentration of $0.35 \% \mathrm{H}_{2}$ was detected at the reactor outlet). This might explain the observed narrow RTD shown in Figure 6.

\section{Conclusions}

(1) The novel design of a membrane reactor with two zones packed by catalytic filaments placed in parallel is proposed.

(2) The hydrodynamic characteristics of the reactor correspond to those of a multichannelled microreactor with laminar flow, a low-pressure drop, and a narrow RTD.

(3) The filamentous catalyst $0.5 \% \mathrm{Pt} / 1.0 \% \mathrm{Sn} / \mathrm{ASF}$ was tested in propane dehydrogenation and showed a high activity (conversion close to the equilibrium value) and suitable stability under periodic regeneration in an oxidative atmosphere.

(4) The presence of a small amount of hydrogen in the gas phase is necessary to maintain catalyst activity by lowering its deactivation.

\section{Notation}

$\mathrm{c}_{\mathrm{i}}=$ number of carbon atoms in compound $\mathrm{i}$

$\mathrm{d}_{\mathrm{eq}}=$ equivalent diameter $(\mathrm{m})$

$\mathrm{F}=$ hydrogen flux $\left(\mathrm{mol} \mathrm{m} \mathrm{m}^{-2} \mathrm{~s}^{-1}\right)$

$\mathrm{L}=$ length $(\mathrm{m})$

$\mathrm{n}=$ molar flow $\left(\mathrm{mol} \mathrm{s}^{-1}\right)$

$\mathrm{p}=$ pressure $(\mathrm{Pa})$

$\mathrm{p}_{\mathrm{I}}, \mathrm{p}_{\mathrm{II}}=$ hydrogen partial pressures in zones I and II, respectively $(\mathrm{Pa})$

$\mathrm{Q}=$ gas flow rate $\left(\mathrm{m}^{3} \mathrm{~s}^{-1}\right)$

$\mathrm{S}=$ selectivity

$\mathrm{T}=$ temperature $(\mathrm{K})$

$\mathrm{t}_{\text {memb }}=$ membrane thickness $(\mathrm{m})$

$\mathrm{X}=$ conversion

$\mathrm{X}_{\mathrm{eq}}=$ equilibrium conversion

$\epsilon=$ porosity

$\mu=$ gas viscosity ( $\mathrm{Pa} \mathrm{s}$ )

$\tau=$ estimated mean residence time (s)

ASF = alumina silica filaments

GHSV = gas hourly space velocity $\left(\mathrm{h}^{-1}\right)$

$\mathrm{ID}=$ internal diameter $(\mathrm{m})$

RTD $=$ residence time distribution

SSA = specific surface area $\left(\mathrm{m}^{2} / \mathrm{g}\right)$

STP $=$ standard temperature and pressure

\section{Acknowledgment}

The authors gratefully acknowledge the financial support of the Swiss National Science Foundation, as well as Dr. I. Youranov and A. Udriot (Institute of Chemical Engineering, EPFL) for the catalyst preparations.

\section{Literature Cited}

(1) Rouge, A.; Spoetzl, B.; Gebauer K.; Schenk, R.; Renken A. Microchannel Reactor for Fast Periodic Operation: The Catalytic Dehydration of I sopropanol. Chem. Eng. Sci. 2001, 56, 1419-1427.

(2) Hoenicke, D.; Wiessmeier. G. Heterogeneously Catalyzed Reactions in a Microreactor. DECHEMA Monogr. 1996, 132, 93107.

(3) Yarusov, I. B.; Zatolokina, E. V.; Shitova, N. V.; Belyi A. S.; Ostrovskii, N. M. Propane Dehydrogenation over Pt-Sn Catalysts. Catal. Today 1992, 13, 655-658.

(4) Kiwi-Minsker, L.; Youranov, I.; Slavinskaia, E.; Zaikovskii V.; Renken A. Pt and Pd Supported on Glass Fiber as Effective Combustion Catalysts. Catal. Today 2000, 59, 61-68.

(5) Hatziantoniou, V.; Andersson, B.; Schöön, N.-H. Mass Transfer and Selectivity in Liquid-Phase Hydrogenation of Nitro Compounds in a Monolithic Catalyst Reactor with Segmented Gas-Liquid Flow. Ind. Eng. Chem. Process Des. Dev. 1986, 25, 964-970.

(6) Scherer, G. W. H. Systems and Economic Analysis of the Seasonal Storage of Electricity with Liquid Organic Hydrides. Ph.D. Dissertation 12440, Swiss Federal Institute of Technology (ETHZ), Zürich, Switzerland, 1997.

(7) Cybulski, A.; Moulijn, J. A. The Present and the Future of Structured Catalysts-An Overview. In Structured Catalysts and Reactors; Cybulski A., Moulijn, J . A., Eds.; Marcel Dekker: New York, 1998.

(8) Ertl, G.; Knözinger, H.; Weitkamp J . Handbook of Heterogeneous Catalysis; VCH Publishers: Weinheim, Germany, 1997.

(9) Sheintuch, M.; Dessau, R. M. Observation, Modeling and Optimization of Yield, Selectivity and Activity during Dehydro- 
Ind. Eng. Chem. Res., Vol. 40, No. 23, 20015239

genation of I sobutane and Propane in a Pd Membrane Reactor. Chem. Eng. Sci. 1996, 51, 535-547.

(10) Lok L. K.; Gadai, N. A.; Gudkov B. S.; Kiperman, S. L.; Kogan, S. B. Investigation of the Kinetics and Mechanism of the Dehydrogenation of I sobutane on Platinum-Tin Catalysts. Kinet. Katal. 1988a, 27, 1365-1370.
Received for review December 12, 2000

Revised manuscript received May 4, 2001 Accepted May 11, 2001

IE001077Z 